\title{
Studies on Thermal Oxidation Stability of Aviation Lubricating Oils
}

\author{
Nan $\mathrm{Wu}^{1,2}$, Zhi-Min Zong ${ }^{1, a}$, Yi-Wei Fei ${ }^{2}$ and Jun $\mathrm{Ma}^{2}$ \\ ${ }^{1}$ Key Laboratory of Coal Processing and Efficient Utilization, Ministry of Education, China University of Mining \& \\ Technology, Xuzhou 221116, China. \\ ${ }^{2}$ Department of Aviation Oil and Material, Air Force Logistics Institute, Xuzhou 221000, China
}

\begin{abstract}
Simulating the operating condition of aviation engine via autoclave experiment of high temperature and pressure, we studied the physic-chemical property of poly- $\alpha$-olefin base oil samples mixed with antioxidants of 2,6-di-tert-butyl-4-methylphenol and p,p'-diisooctyl diphenylamine at different temperature. The mechanism of degradation of PAO aviation lubricating oil was analyzed according to the oxidized products by modern analytical instruments. The results showed that the aviation lubricating oil produced a large number of low molecule compounds while increasing the temperature, and resulted in the viscosity decreasing and acid value increasing which indicated that the thermal oxidation of the oil sample underwent a radical process.
\end{abstract}

\section{Introduction}

Lubricating oils help lubricate, clean, and cool aircraft engines during operation [1,2]. The thermal oxidation stability of lubricating oil is a pivotal indicator of its quality, which directly affects the normal operation of the aircraft as well as the service life of the equipment $[3,4]$. In recent years, the structure of aircraft engines has become more complex, and there is a need for aviation lubricating oils that can be used in harsh working environments. High temperature and pressure conditions as well as high shear conditions have increased the demand for aviation lubricating oils with high thermal oxidation stabilities. Degradation of the lubricating oil can have extremely adverse effects on aircraft engine performance and result in major accidents, including plane crashes.

Previous studies on aviation lubricating oils have indicated that the oils undergo obvious changes inside the engines. The oils turn darker, their viscosity increases, and they form a large number of deposits. Therefore, in order to ensure flight safety, it is essential to elucidate the thermal oxidation degradation behavior of aviation lubricating oils.

The aviation lubricating oil investigated in this study consisted of a synthetic poly- $\alpha$-olefin (PAO) oil (the base oil) to which 2,6-di-tert-butyl-4-methylphenol (DBPC) and p,p'-diisooctyl diphenylamine (DODPA) were added as antioxidants. Other additives such as detergent-based dispersants and friction-modifying agents were not used. The normal operational temperature of aviation lubricating oils is approximately $200^{\circ} \mathrm{C}$; however, it increases to $250-300^{\circ} \mathrm{C}$ while the engine is slowing or shutting down, because the amount of air flowing into the engine decreases or the flow of air stops

\footnotetext{
${ }^{a}$ Corresponding author:515811945@qq.com
} 
completely, and the bearings are cooled primarily by the lubricating oil [5-8]. Therefore, it is important to obtain more reliable data on the lubricating oil at high temperatures, as this will allow effective use of the oil.

As stated above, the oil samples used in this study were prepared by mixing the PAO base oil with DBPC and DODPA as antioxidants. The physicochemical properties of the oil at different temperatures and pressures were tested in an autoclave, which was used to simulate the operating conditions of an aircraft engine. Finally, based on the oxidation products formed at high temperatures, which were analyzed using a variety of modern analytical techniques, a mechanism to explain the degradation of PAO-based aviation lubricating oils by thermal oxidation is proposed.

\section{Experimental}

\subsection{The main materials and equipment}

6890/5973 GC/MS, American Agilent Company; IR-560, American Nicolet magna Company; high temperature and pressure autoclave, self-made.

\subsection{Preparation of experimental oil sample}

Taken 50g PAO base oil and the mixture of $50 \mathrm{~g}$ PAO base oil, $0.25 \mathrm{~g}$ DBPC and $0.25 \mathrm{~g}$ DODPA into $500 \mathrm{~mL}$ autoclave and stirred at speed of $800 \mathrm{r} / \mathrm{min}$ and kept the temperatures of $170^{\circ} \mathrm{C}, 200^{\circ} \mathrm{C}, 230^{\circ} \mathrm{C}$, $270^{\circ} \mathrm{C}$ and $300^{\circ} \mathrm{C}$ for $2 \mathrm{~h}$. After the reaction putted the reactor into an ice-water bath to cool to room temperature, then toke out the oil sample. For the convenience of description, the products of PAO crude oil at room temperature and other oil sample at $170^{\circ} \mathrm{C}, 200^{\circ} \mathrm{C}, 230^{\circ} \mathrm{C}, 270^{\circ} \mathrm{C}$ and $300^{\circ} \mathrm{C}$ reaction were marked as P20, P170, P200, P230, P270, P300; the products of mixture oil with antioxidants were labeled as $\mathrm{P}^{\prime} 20, \mathrm{P}^{\prime} 170, \mathrm{P}^{\prime} 200, \mathrm{P}^{\prime} 230, \mathrm{P}^{\prime} 270$ and $\mathrm{P}^{\prime} 300$.

\section{Results and Discussion}

\subsection{Changes of Kinematic Viscosity and Acid Value of the Oil Sample}

The kinematic viscosity of the oil sample oxidized at different temperature were shown in Table 1 .

TABLE 1. Kinematic viscosity at $40^{\circ} \mathrm{C}$ and acid value of the oil samples

\begin{tabular}{|c|c|c|c|}
\hline Item & $\begin{array}{c}\text { kinematic viscosity }\left(40^{\circ} \mathrm{C}\right) \\
/\left(\mathrm{mm}^{2} \sqsubset \mathrm{s}^{-1}\right)\end{array}$ & Item & $\begin{array}{c}\text { kinematic viscosity }\left(40^{\circ} \mathrm{C}\right) \\
/\left(\mathrm{mm}^{2} \square \mathrm{s}^{-1}\right)\end{array}$ \\
\hline $\mathrm{P}_{20}$ & 17.94 & $\mathrm{P}^{\prime}{ }_{20}$ & 18.39 \\
\hline $\mathrm{P}_{170}$ & 17.97 & $\mathrm{P}^{\prime}{ }_{170}$ & 18.89 \\
\hline $\mathrm{P}_{200}$ & 17.88 & $\mathrm{P}^{\prime}{ }_{200}$ & 18.11 \\
\hline $\mathrm{P}_{230}$ & 17.23 & $\mathrm{P}^{\prime}{ }_{230}$ & 17.79 \\
\hline $\mathrm{P}_{270}$ & 14.39 & $\mathrm{P}_{270}$ & 17.56 \\
\hline $\mathrm{P}_{300}$ & 8.28 & $\mathrm{P}^{\prime}{ }_{300}$ & 12.40 \\
\hline
\end{tabular}

It can be seen from Table 1 that the viscosity of the PAO oil sample mixed with antioxidants was slightly greater than PAO base oil, which may be due to the steric structure of the antioxidant dissolved increasing the flow resistance of the lubricating oil[9-11]. Enhancing the temperature, the viscosity of the PAO base oil decreased gradually, what's more, when the temperature rose to above $230^{\circ} \mathrm{C}$ it declined sharply. However, there is no obviously changes at lower temperature (less than 
$230^{\circ} \mathrm{C}$ ). While the viscosity of the PAO oil samples mixed with the antioxidants decreased flatly as long as the temperature increasing, but when the reaction temperature was higher than $270^{\circ} \mathrm{C}$, it would change greatly. As can be seen from Table 1, the viscosity of the PAO base oil decreased from 17.97 $\mathrm{mm}^{2} \cdot \mathrm{s}^{-1}$ to $8.28 \mathrm{~mm} \cdot \mathrm{s}^{-1}$ with decline of $53.9 \%$, while the decline of the viscosity of the PAO oil samples was $34.4 \%$ with the attenuation decreasing. Generally, the oxidation stability of PAO oil would be enhanced by adding antioxidants which effectively inhibited the viscosity attenuation of the lubricating oil.

\subsection{Changes of oil samples' composition}

\subsubsection{FTIR Analysis}

Fig. 1 shows the infrared spectra of the products oxidized at different temperature of PAO base oil and PAO oil samples mixed with antioxidants.

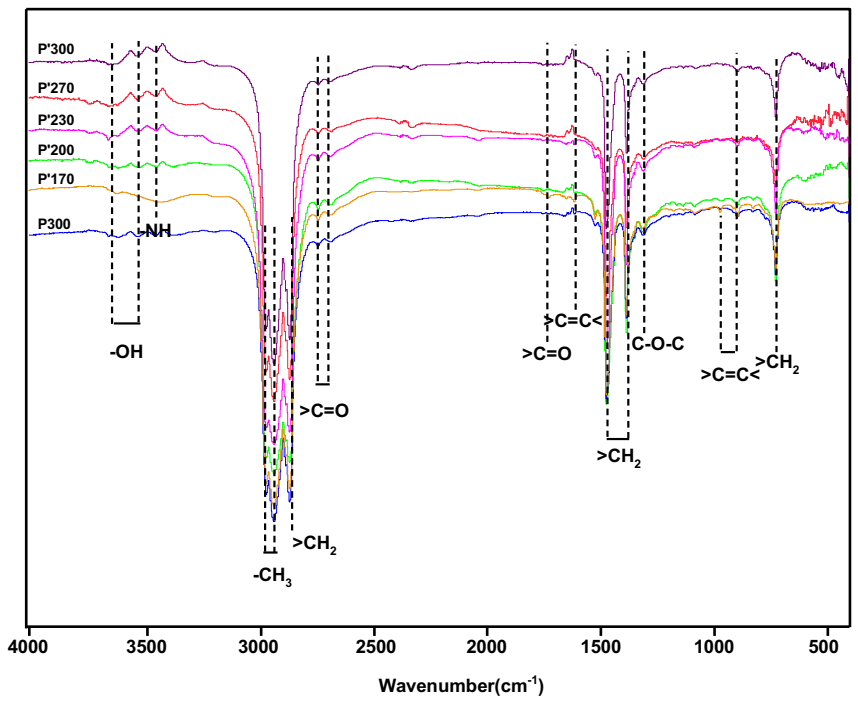

Figure 1. Infrared spectra of PAOs after oxidation test

As can be seen from Figure 1, the strong absorption peak at $2975-2850 \mathrm{~cm}^{-1}$ descripts a large number of functional groups of $-\mathrm{CH}_{3}$ and $-\mathrm{CH}_{2}-$; the sharp and strong absorption peak at $721 \mathrm{~cm}^{-1}$ descripts many units connected by more than four groups of $-\mathrm{CH}_{2}-$; the broad absorption peak at 3650$3429 \mathrm{~cm}^{-1}$ descripts groups of $-\mathrm{OH}$ and-NH; the small and weak peaks at $2730 \mathrm{~cm}^{-1}$ and $1741 \mathrm{~cm}^{-1}$ descript groups of $\mathrm{C}=\mathrm{O}$; the peaks at $966 \mathrm{~cm}^{-1}$ and $888 \mathrm{~cm}^{-1}$ descript groups of $\mathrm{C}=\mathrm{C}$. The presence of $\mathrm{OH}, \mathrm{C}=\mathrm{O}, \mathrm{C}=\mathrm{C}$ and other functional groups in the infrared spectra shows that the PAO lubricating oil was oxidized to decay under high temperature and generated olefins, alcohols, acids and other products[12-15]. But the infrared spectra can't descript the effects of antioxidants on the oil sample degradation quantitatively because of the little amount of products.

\subsubsection{GC/MS analysis}

Fig. 2 and 3 show the ion chromatogram of the products oxidized at different temperature of PAO base oil and PAO oil samples added with antioxidants. The GC/MS chromatogram of former 17 min retention time was mainly studied, because the compounds detected in the chromatogram of the later part were mainly polymers. The category and relative content of the products oxidized such as nalkanes, iso-paraffins and olefins are shown in Table 2. 


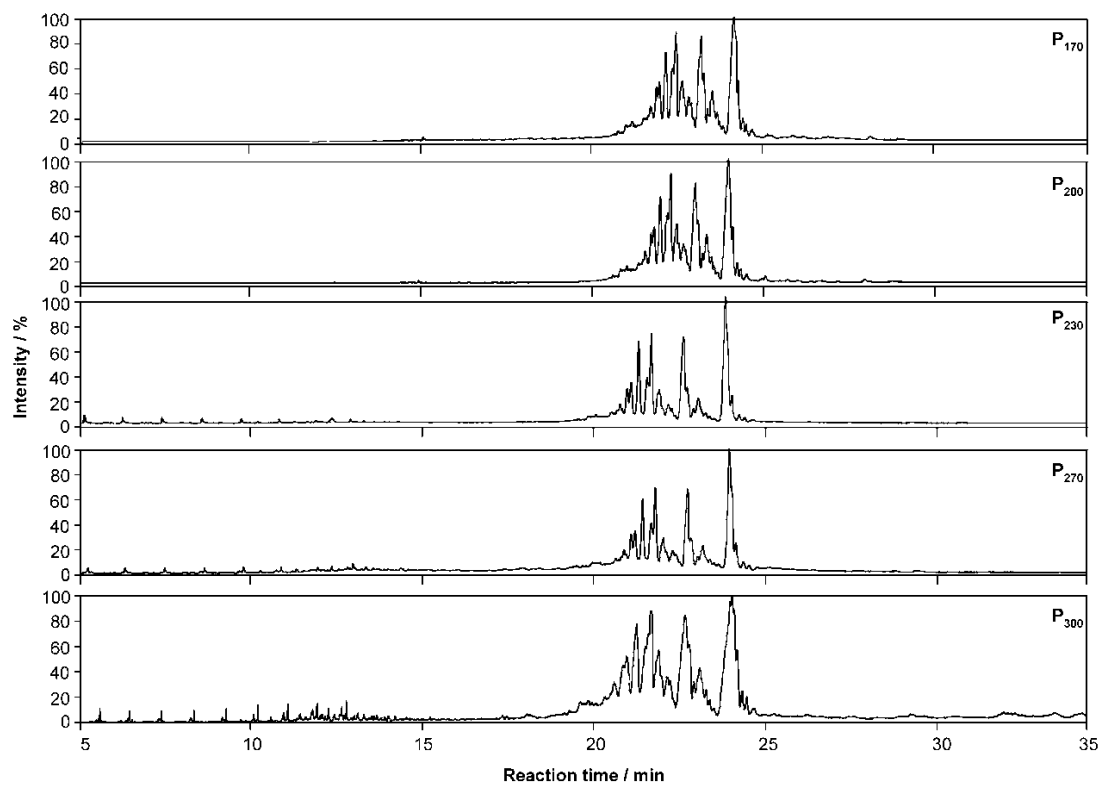

Figure 2. The ion chromatogram of PAOs after oxidation test

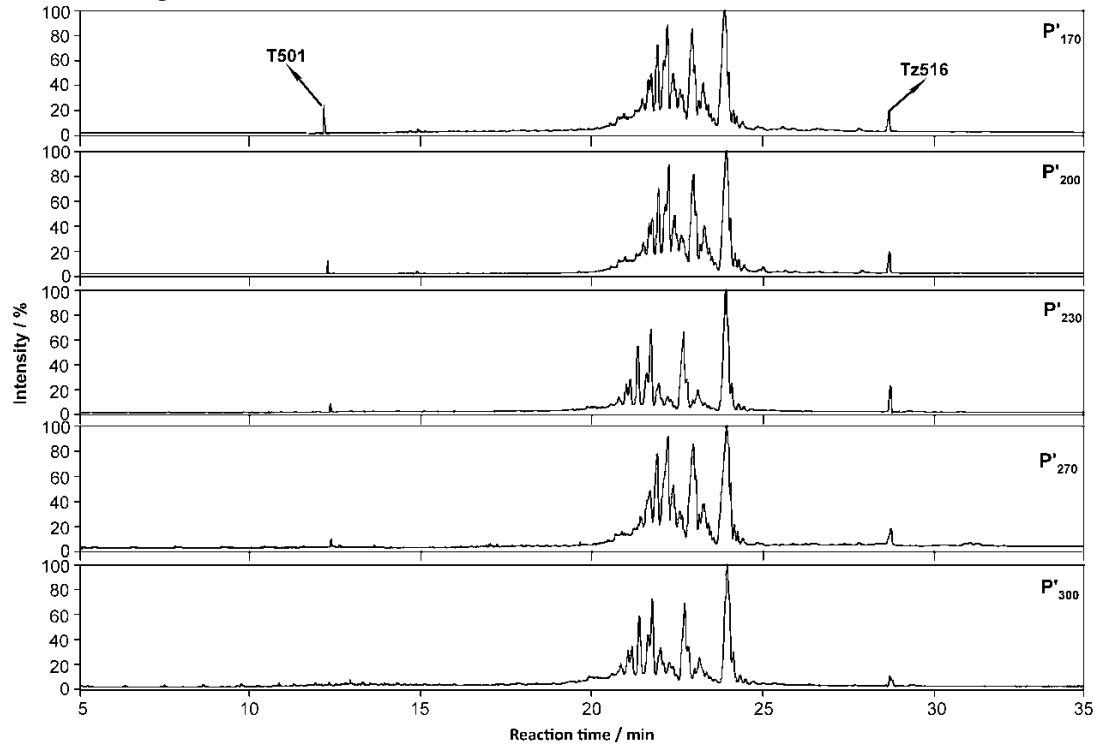

Figure 3. The ion chromatogram of PAOs added antioxidants after oxidation test

Table 2 Category and relative content of PAOs after oxidation test

\begin{tabular}{ccccccccc} 
& \multicolumn{2}{c}{ n-alkanes } & & \multicolumn{2}{c}{ iso-paraffin } & & \multicolumn{2}{c}{ olefin } \\
\cline { 2 - 3 } Item & category & $\begin{array}{c}\text { relative } \\
\text { content } \\
(\%)\end{array}$ & & category & $\begin{array}{c}\text { relative } \\
\text { content } \\
(\%)\end{array}$ & & category & $\begin{array}{c}\text { relative } \\
\text { content } \\
(\%)\end{array}$ \\
\hline $\mathrm{P}_{170}$ & 2 & 0.067 & & 4 & 0.370 & & 5 & 0.224 \\
$\mathrm{P}_{200}$ & 5 & 0.316 & & 4 & 0.493 & & 5 & 0.481 \\
$\mathrm{P}_{230}$ & 7 & 0.558 & & 4 & 0.658 & & 6 & 0.684 \\
\hline
\end{tabular}




\begin{tabular}{lcccccc}
\hline $\mathrm{P}_{270}$ & 12 & 2.675 & 10 & 1.113 & 21 & 3.817 \\
$\mathrm{P}_{300}$ & 35 & 8.606 & 25 & 3.538 & 47 & 9.968 \\
$\mathrm{P}^{\prime}{ }_{170}$ & 2 & 0.053 & 3 & 0.281 & 2 & 0.132 \\
$\mathrm{P}^{\prime}{ }_{200}$ & 2 & 0.282 & 4 & 0.360 & 2 & 0.359 \\
$\mathrm{P}^{\prime}{ }_{230}$ & 3 & 0.498 & 4 & 0.459 & 5 & 0.664 \\
$\mathrm{P}^{270}$ & 10 & 2.607 & 7 & 0.998 & 13 & 3.085 \\
$\mathrm{P}{ }_{300}$ & 34 & 8.368 & 18 & 3.316 & 41 & 9.324 \\
\hline
\end{tabular}

It can be found that the molecular ion peak of small molecules gradually increased with the increase of reaction temperature and the peak area also increased accordingly, which indicates that the PAO oil samples decayed seriously in the oxidation reaction at high-temperature and the long-chain molecules of PAO oil broke to some alkanes, alkenes and other short-chain molecules. The degradation of PAO oil samples weakened significantly after adding antioxidants, while antioxidant itself consumed constantly and the peak area decreased gradually.

Table 2 shows that the oxidation products of PAO base oil at $170^{\circ} \mathrm{C}$ were 2 kinds of n-alkanes, 4 kinds of iso-paraffins and 5 kinds of olefins and the relative contents were $0.067 \%, 0.370 \%$ and $0.224 \%$ respectively. While enhanced the temperature to $300^{\circ} \mathrm{C}$, the molecular chain structure was severely damaged to generate oxidation products of 35 kinds of n- alkanes, 25 kinds of iso-paraffins, 47 kinds of olefins and the relative contents were 8.606\%, 3.538\% and 9.968\%. Generally, the enhancement of temperature resulted in the deepen cracking of molecular and produced many small molecular compounds to increase the fluidity of lubricating oil itself. The kinematic viscosity decreased because intermolecular interaction weakened and intermolecular friction reduced.

When we added antioxidants into PAO base oil, the oil sample also went degradation along with the temperature increasing. But the categories and relative contents of the products after thermal oxidation reaction were less than that of PAO base oil without antioxidants, especially category and relative quality of olefins decreased greatly. There were 5 kinds of olefins in the products oxidized of PAO base oil with relative contents of $0.481 \%$ at $230^{\circ} \mathrm{C}$; while adding antioxidants, there were 2 kinds of olefins with relative contents of $0.359 \%$ and reduction of $25 \%$. Thus, antioxidants may effectively retard the thermal oxidation reaction of PAO lubricating oil and inhibit the formation of olefins

\section{Conclusions}

The present study revealed that antioxidants could enhance the thermal oxidation stability of PAO aviation lubricating oil as the decay process of the oil sample was significantly slowed down. Analyzed with IR and GC/MS instruments, we found that during the thermal oxidation step, PAO lubricating oil underwent a free radical chain reaction process, following pyrolysis and thermal oxidation reaction mechanism.

\section{Acknowledgements}

This work was subsidized by the Jiangsu Provincial Natural Science Foundation of China (Grant BK20161187), and Xuzhou Science and Technology Development Funds (Grant KC16SG269).

\section{References}

1. B. K. Sharma, A. J. Stipanovic, Thermochimica Acta 402, 1-18 (2003).

2. J. S. Basta, Petroleum Science \&Technology 28, 1611-1619 (2010). 
3. K. S. Pedersen, H. P. Ronningsen, Energy Fuels 17, 321-330 (2003).

4. C. D. Gamlin, N. K. Dutta, N. R. Choudhury, et al., Thermochim Acta, 357, 392-393 (2002).

5. H. Diamond, H. C. Kennedy, R. G. Larsen, Chemistry \&Physics of Lipids, 176, 99-104 (2013).

6. R. G. Larsen, R. E. Thorpe, F. A. Armfield. Ind. Eng. Chem. 34, 183-193(2002).

7. G. Kreisberger, C. W. Klampfl, W. W. Buchberger, Energy Fuels, 10, 1021-1025 (2016).

8. M. J. Abedin, H. H. Masjuki, M. A. Kalam, et al. Energy Conversion \& Management, 85, 173189 (2014).

9. R. Shah, D. A. Pratt, J. Org. Chem., 81, 6649-6656(2016).

10. R. G. Larsen, F. A. Armfield. Ind. Eng. Chem. 35, 581-588 (2002).

11. M. J. Yanjarappa, S. Sivaram, Prog. Polym. Sci. 27, 1347-1398 (2002).

12. J.C. O. Santos, I. M. G. Santos, A. G. Souza, et al., Fuel 83, 2393-2399 (2004).

13. Y. Si, E.T. Samulski, Nano Lett. 8, 1679-1682(2008).

14. A. Bagri, C. Mattevi, M. Acik, Y.J. Chabal, M. Chhowalla, V.B. Shenoy, Nat. Chem. 2, 581-587 (2010).

15. D.W. Le, V.L. De Los Santos, J.W. Seo, J. Phys. Chem. B 114, 5723-5728 (2010). 